\title{
Hydrogen pump for hydrogen recirculation in fuel cell vehicles
}

\author{
Wilhelm Wiebe ${ }^{1 *}$, Thomas v. Unwerth ${ }^{2}$ and Sven Schmitz ${ }^{3}$ \\ ${ }^{1}$ M.Eng. Wilhelm Wiebe, DHBW Mannheim \\ ${ }^{2}$ Prof. Dr.-Ing. Thomas von Unwerth, Technische Universität Chemnitz \\ ${ }^{3}$ Prof. Dr.-Ing. Sven Schmitz, DHBW Mannheim
}

\begin{abstract}
A promising alternative to fossil-fuelled vehicles are batterypowered vehicles and fuel cell (FC) vehicles. The major differences between fuel cell and battery-powered vehicles are the range and refuelling times of each vehicle type. With a hydrogen $\left(\mathrm{H}_{2}\right)$ fuelling time of approx. 5 minutes it is possible to cover a distance of up to $800 \mathrm{~km}$ with a fuel cell vehicle. These properties make a fuel cell vehicle comparable to a fossil fuel powered vehicle. Furthermore, due to short fuelling times and long range capabilities, fuel cell vehicles are more suitable for long-distance, trucking and agriculture than battery-powered vehicles. The aim of current research is to increase the profitability of fuel cells by reducing costs and improving performance. To ensure a high performance of the fuel cell stack, more hydrogen is supplied to the stack than is needed for the reaction. Therefore, unused hydrogen is pumped back to the anode inlet of the FC-stack using a jet pump or a recirculation blower. In this study, the application of an electrochemical compressor or hydrogen pump (HP) for hydrogen recirculation is suggested. The hydrogen pump is an innovative $\mathrm{H}_{2}$ transport technology with the additional functions of compression and purification in the recirculation system. Hydrogen pumps are very efficient compared to mechanical compressors due to the almost isothermal conditions they operate under. Furthermore, due to the modular design, hydrogen compressors can utilize a minimal amount of space in vehicles.
\end{abstract}

Keywords: Hydrogen pump, electrochemical compressor, fuel cell, hydrogen recirculation, hydrogen purification, hydrogen efficiency, electric power consumption, efficiency of electric drives.

\section{Introduction}

\subsection{Short Description of the Necessity for Recirculation}

In the operation of a fuel cell hydrogen is typically supplied in excess to prevent local hydrogen starvation on the membrane electrode assembly (MEA) and to increase the life of the fuel cell. The hydrogen ratio $\boldsymbol{\lambda}_{\mathbf{H}_{2}}$ can be calculated using Eq. (1),

$$
\lambda_{\mathrm{H}_{2}}=\dot{\mathrm{n}}_{\mathrm{H}_{2}, \mathrm{FC}, \mathrm{in}} / \dot{\mathrm{n}}_{\mathrm{H}_{2}, \mathrm{FC}, \mathrm{use}} \text {. }
$$

With the use of a passive jet pump, an active recirculation blower, or a combination of both, the unused hydrogen is pumped back to the anode inlet and combined with fresh hydrogen from the tank (Fig.1).

\footnotetext{
* Corresponding author: wwiebe@dhbw-mannheim.de
} 


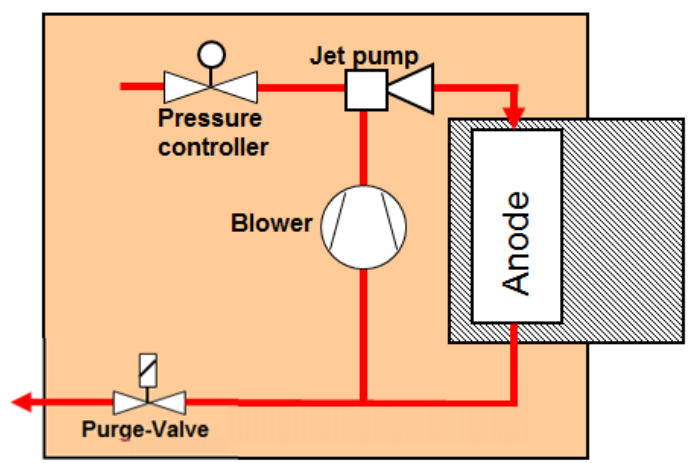

Fig.1. Hydrogen recirculation with jet pump and blower

Due to the diffusion and permeation through the membrane, a parasitic exchange of gases takes place (Fig.2). Hydrogen and oxygen oxidize to water vapour, causing additional humidification of the MEA.

Nitrogen permeation through the membrane is responsible for a concentration of inert gases on the anode side and prevents a uniform reaction from occurring. A less uniform reaction due to the presence of nitrogen inherently causes a decrease in FC performance. For this reason, the anode gas is released at regular intervals with a purge-valve to remove the nitrogen from the system (Fig.1). However, purging also causes the loss of hydrogen, lowering the efficiency of the system.

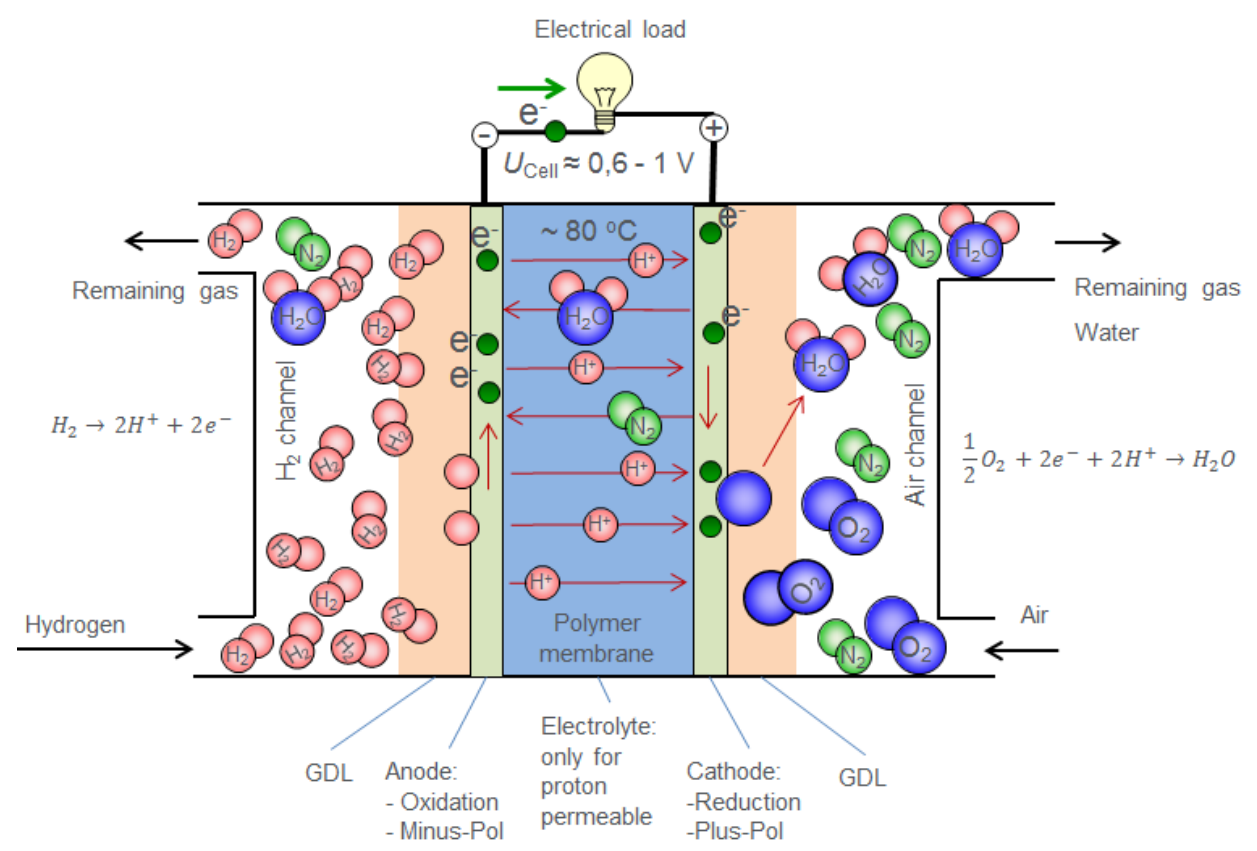

Fig.2. Gas diffusion through the FC-membrane

\subsection{Replacement of the Blower by a Hydrogen Pump}

This study proposes a new option for recirculating hydrogen in a fuel cell system in the form of an electrochemical compressor. The electrochemical compressor, also called hydrogen pump (HP) may be a modified polymer electrolyte membrane fuel cell which is 
connected to a constant current electrical current source for pumping hydrogen. Thus, there is no electrochemical energy conversion as in a fuel cell, but a hydrogen transport and an increase in pressure without mechanically moving components.

\subsection{Function of a Hydrogen Pump}

The structure of the electrochemical compressor is very similar to a FC. Like a fuel cell, the HP consists of an anode, a cathode and an electrolyte. The electrolyte of the HP is a polymer electrolyte membrane (PEM). By applying an electrical potential from an external constant current source, the hydrogen is forced to split up into protons and electrons. The difference in potential leads to a transport of the protons to the cathode side through the membrane. Contrary to the fuel cell, however, no gas is supplied to the electrochemical compressor on the cathode side. Thus, no reaction between hydrogen and oxygen is possible. At the cathode side, the electrons and protons recombine again to hydrogen and continuous pumping increases the pressure on the cathode side in a closed system.

Fig. 3 shows how the hydrogen pumping action separates gases as only hydrogen protons are pumped through the membrane. Other gases such as nitrogen are unaffected by the pumping action, and remain on the anode side where they can be purged. Other gases can only transport from the anode to the cathode side of the HP by diffusion processes.

When integrating a hydrogen pump with polymer membrane (PEM-HP) into a fuel cell system, the electrochemical compression has the following advantages compared to the mechanical compression:

- The recirculated hydrogen is purified from a hydrogen-containing gas mixture and passed to the FC, thereby increasing the efficiency of the FC.

- All contamination in the anode gas is purged and the anode purge flow of the HP contains little or no amounts of hydrogen, minimizing the loss of the hydrogen from the tank.

- In nearly isothermal conditions, the HP has a higher efficiency compared to mechanical compressors.

- HPs are sturdy and have low maintenance costs because they contain no moving parts. Compared to noisy mechanical compressors, there is no risk of contamination of the hydrogen from oil particles and abrasion.

- HPs require the same components of fuel cells, making them modular and simple to integrate into a fuel cell stack (anode, cathode, and electrolyte). Therefore, and HP and fuel cell system requires significantly less space than mechanical alternatives to HPs.

The main functions of the HP in the proposed application are the separation of hydrogen from the fuel cell exhaust mixture and the pumping of the extracted hydrogen [1]. In the literature, other possible applications for the hydrogen pump are proposed such as the

- hydrogen compression for storage [2],

- hydrogen purification [3, 4]. 


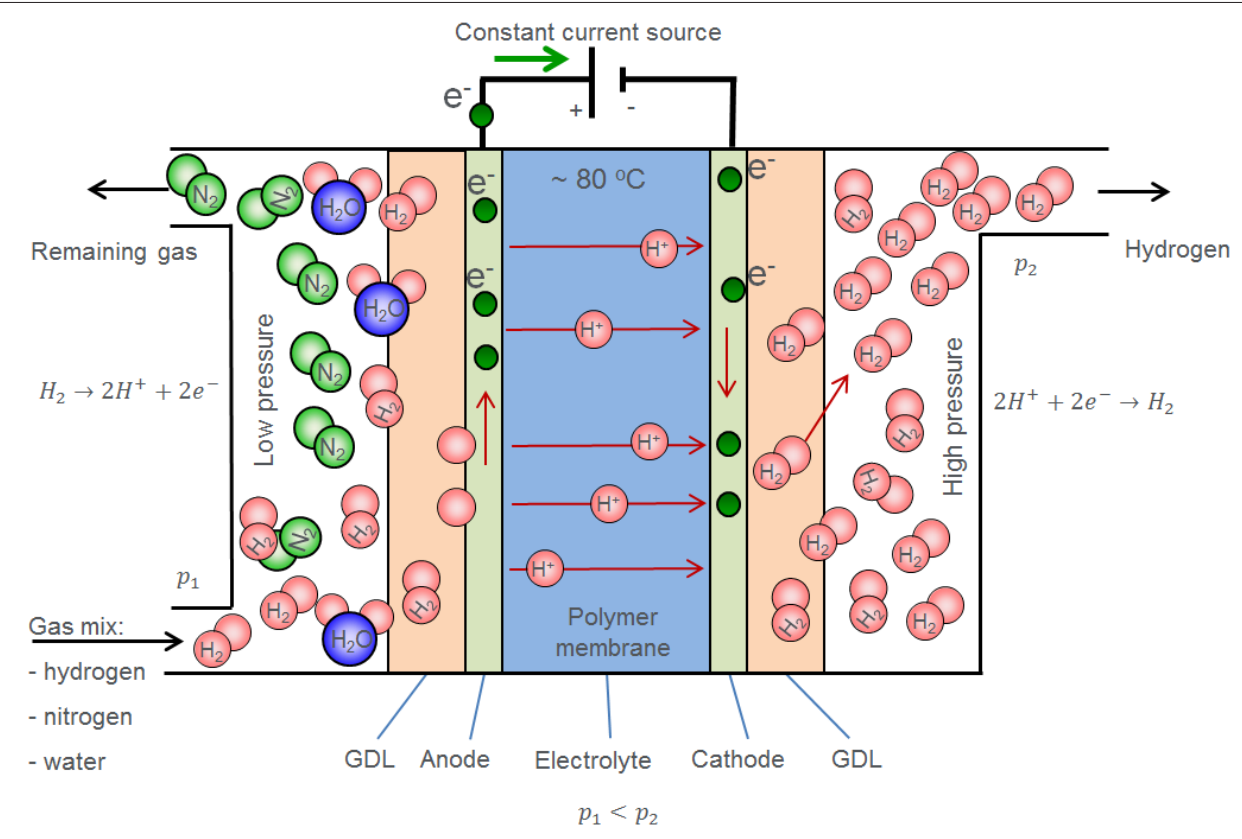

Fig.3. Schematic overview of a hydrogen pump

\section{Experimental and Numerical Methods}

\subsection{Simulation}

Within the scope of this work simulations were performed using Comsol Multiphysics. The aim of this work is the theoretical design and optimization of a hydrogen pump for hydrogen recirculation in an automotive fuel cell system.

With the findings from the simulation, the potential of the HP should be more accurately estimated and can be validated through experimentation.

The simulation includes a complete fuel cell system with a HP with an active area of $20 \mathrm{~cm}^{2}$ and considers all electrochemical processes. The focus of the simulations is the mass transport through the membrane of the HP. The gases involved and their transport processes are examined closely and a prediction for the scaling of the PEM-HP to typical effective areas in fuel cell vehicles of 320 to $400 \mathrm{~cm}^{2}$ is made.

\subsection{Experiment}

The theoretical relationship between the current density and the resulting volume was experimentally tested to determine if the relationship follows the Faraday law without any restrictions.

For the experiments, Umicore pMembrain H300 MEA's with an active membrane area of $100 \mathrm{~cm}^{2}$ and a membrane thickness of $25 \mu \mathrm{m}$ were used. Carbon electrodes with a platinum loading of $0.4 \mathrm{mg} / \mathrm{cm}^{2}$ were applied directly on each side of the membrane as the anode and cathode. A Sigracet GDL 10 BB gas diffusion layer (GDL) with a slightly larger dimension of $103 \mathrm{~cm}^{2}$ was also applied directly to the electrodes. The flow distributor for the hydrogen and oxygen side consists of two laser-welded stainless steel sheets, each embossed with an 8 -fold meander. The interspace of the welded sheets was used for the transport of demineralized water for the cooling of the cell. 
Fig. 4 shows the schematic structure of the HP in the test bench. A gas mixture of $60 \% \mathrm{H}_{2}$ and $40 \% \mathrm{~N}_{2}$ was supplied from the gas tank. After setting the flow rate by a mass flow controller, humidified hydrogen was fed to the anode inlet. The pressures and temperatures as well as the $\mathrm{H}_{2}$ mole fraction were also measured.

Several experiments were carried out with a gas mixture of $60 \% \mathrm{H}_{2}$ and $40 \% \mathrm{~N}_{2}$ at different temperatures $\left(50-90{ }^{\circ} \mathrm{C}\right)$ and relative humidity (60-90 \% r.H.).

The cell temperature was initially set to $60{ }^{\circ} \mathrm{C}$ and relative humidity was set to $60 \%$. The operating pressure was 1.5 bar at the HP anode side and 1.6 bar at the cathode side.

The hydrogen pump was operated at a constant flow rate and the voltage-current characteristics were recorded.

On the cathode side, the relative humidity transferred by electroosmotic drag was first measured. After the separator, the flow rate, temperature, and $\mathrm{H}_{2}$-mole fraction of dry hydrogen were determined. Subsequently, the flow rates from the experiment were compared with the theoretical flow rates according to Faraday's law with direct dependence on the current. In the next step, the series of measurements with higher temperatures and/or humidities were repeated. In parallel, reference cells have been taken from the literature and have been compared with the experimental results.

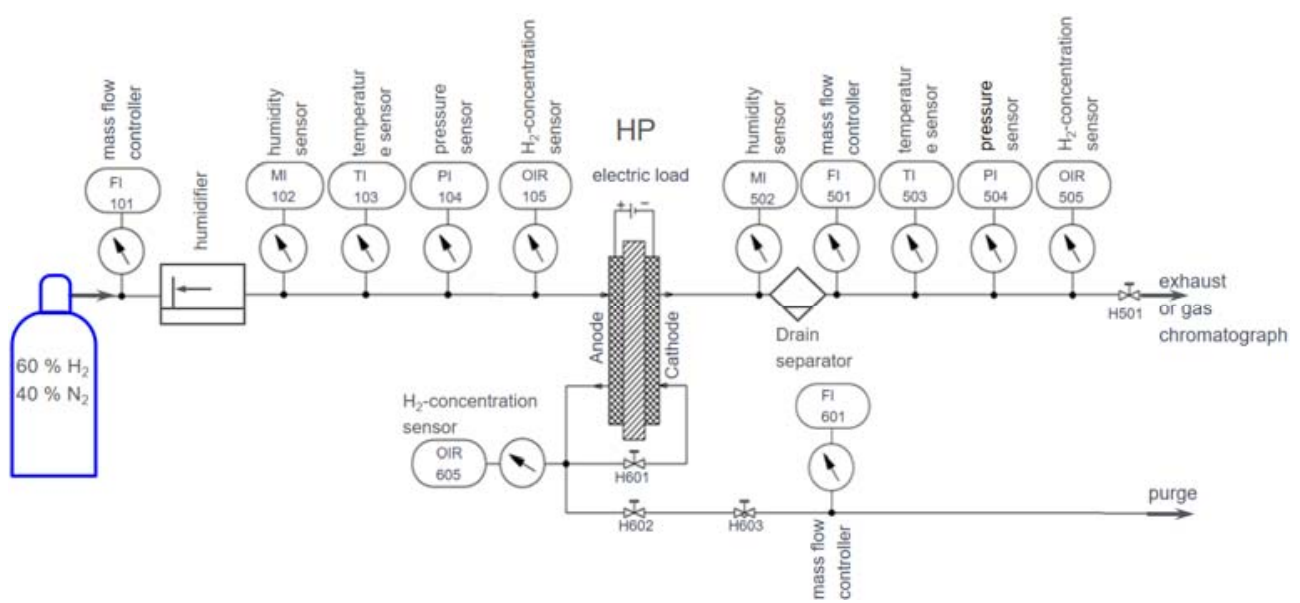

Fig.4. Schematic diagram of experimental apparatus of hydrogen pump and PEMFC.

\section{Results and Discussion}

\subsection{Inert Gas Discharge}

The aim of this study was to separate the hydrogen from the hydrogen mixture with a gas composition of $60 \% \mathrm{H}_{2}$ and $40 \% \mathrm{~N}_{2}$, to examine the hydrogen purity at the HP cathode output. The cleaning effect by the HP was confirmed in the experiments. After operation of the HP, the concentration of the gas mixture on the cathode side was $\sim 99.5 \% \mathrm{H}_{2}$ and only $0.5 \%$ of nitrogen (Fig. 5 ).

In the experimental studies with a gas composition between 2 and $5 \% \mathrm{~N}_{2}$ at the anode inlet, which are similar to the realistic nitrogen content in the vehicles, the nitrogen content at the cathode was so small that the sensors were not able to detect it. Further examination of the cathode gas content with a gas chromatograph indicated a nitrogen content of $\sim 20-40 \mathrm{ppm}$. 

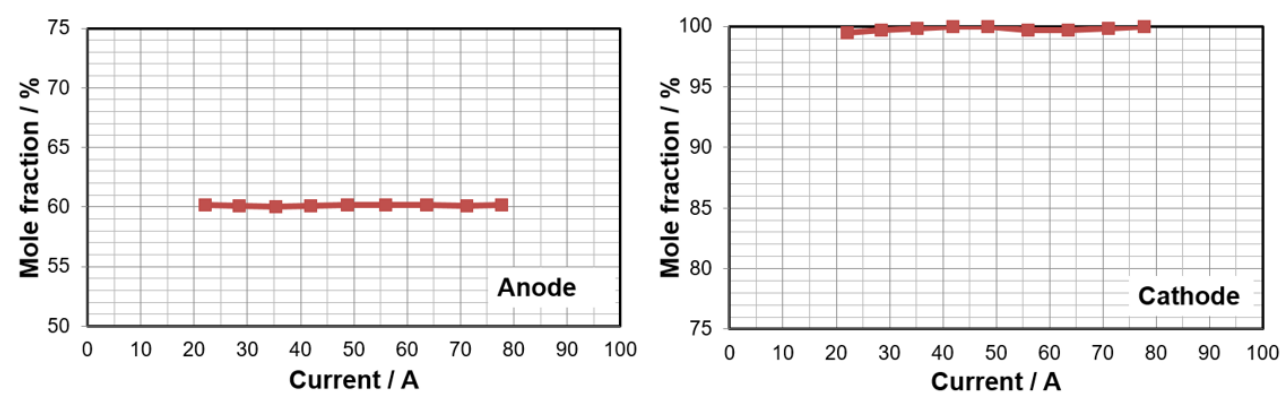

Fig.5. Mole fraction of $60 \% \mathrm{H}_{2}$ gas mixture on the anode side and $\sim 99,5 \%$ on the cathode side as a function of the current at $80{ }^{\circ} \mathrm{C}$ and $80 \%$ r.H.

In the simulation, the nitrogen excretion was investigated with a nitrogen content of $4 \%$ at the anode inlet. During the pumping process, the hydrogen was pumped to the cathode side which reduced the hydrogen mole fraction at the anode along the channel. The total volume flow rate decreased and there was a nitrogen enrichment from $4 \%$ to $\sim 40 \%$.

Nitrogen diffusion and permeation from the anode to the cathode also happens in a HP, but in a much smaller amount than in a FC. Thus, the $\mathrm{N}_{2}$ mole fraction is shown in Fig. 6 on the anode as a percentage while the cathode side in $\mathrm{ppm}$. The highest mole fraction of $\sim 80 \mathrm{ppm}$ of nitrogen was found in the dead end area of the cathode. At the cathode exhaust, the nitrogen content mixes with the pumped hydrogen and the concentration falls to $\sim 40 \mathrm{ppm}$.
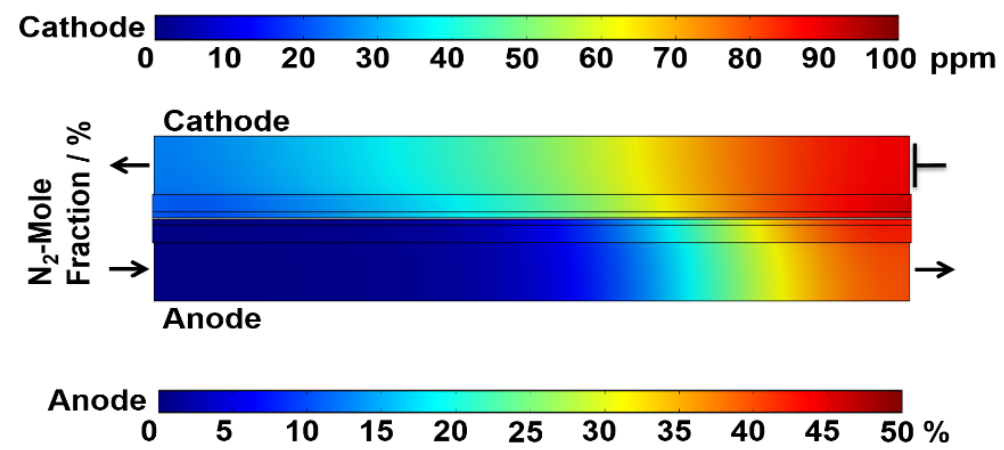

Fig.6. Results of the simulation study. Reduction of nitrogen from $4 \%$ on the anode to $\sim 40$ ppm on the cathode

\subsection{Water Balance}

In the vehicle recirculation circuit, the $\mathrm{N}_{2}$-contaminated hydrogen is humidified in the FC. $\mathrm{H}_{2}$ is transported and cleaned by the HP from the anode to the cathode side. Similar to the fuel cell, in the HP water vapour is also transported through electroosmotic drag, diffusion and permeation from the anode to the cathode. The amount of water vapour transported through the HP membrane depends on the humidity supplied to the HP anode inlet. In the experiment and in the simulation, the relative humidity at the HP anode inlet was increased from $60 \%$ to $90 \%$ and the effects on the U-I characteristic were observed.

The aim was to achieve the highest possible relative humidity at the HP cathode output without exceeding the saturation limit. In the experiment, the best U-I characteristic was found at a relative humidity of $80 \%$ and a temperature of $80^{\circ} \mathrm{C}$ (Fig.7). 

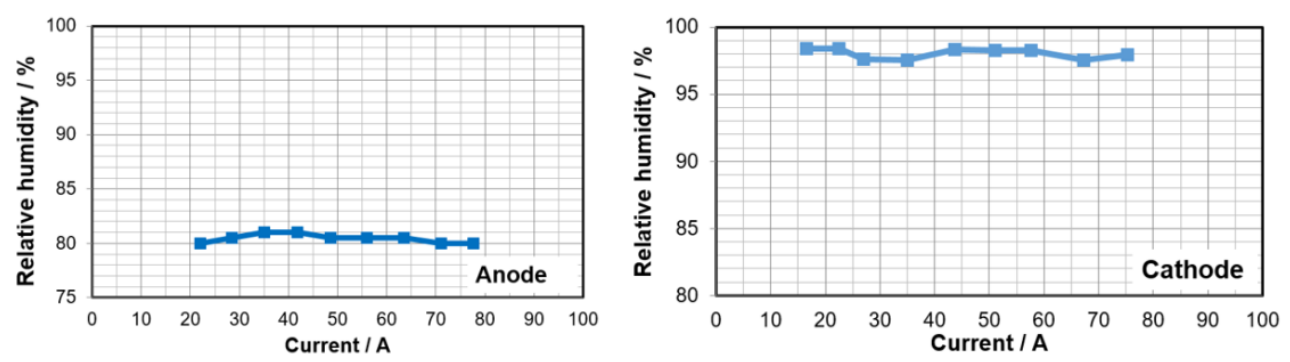

Fig.7. Results of the experimental study. The relative humidity increases from anode to cathode with the increase of the partial pressure.

In the simulation, the optimal air humidity could also be determined by the varying of the HP temperature and the relative humidity at the HP anode inlet.

The relative humidity of the HP cathode is defined by two factors. The main factor is the supply of humidified hydrogen to the HP anode inlet. The more water contained in the supplied gas, the more water is transported to the cathode side. The second factor is the increasing of the relative humidity from the anode to the cathode side due to the increase in pressure. Since the relative humidity represents the ratio of the water partial pressure to the vapour pressure, the relative humidity increases with increasing pressure.

By varying the HP temperature and relative humidity at the HP anode inlet, the optimum humidity was determined. At a relative humidity of approx. $85 \%$ at the anode inlet with a pressure difference of $100 \mathrm{~Pa}$, the gas on the cathode side did not exceed saturation. The cathode gas at the outlet has a maximum relative humidity of $92.5 \%$ (Fig.8).

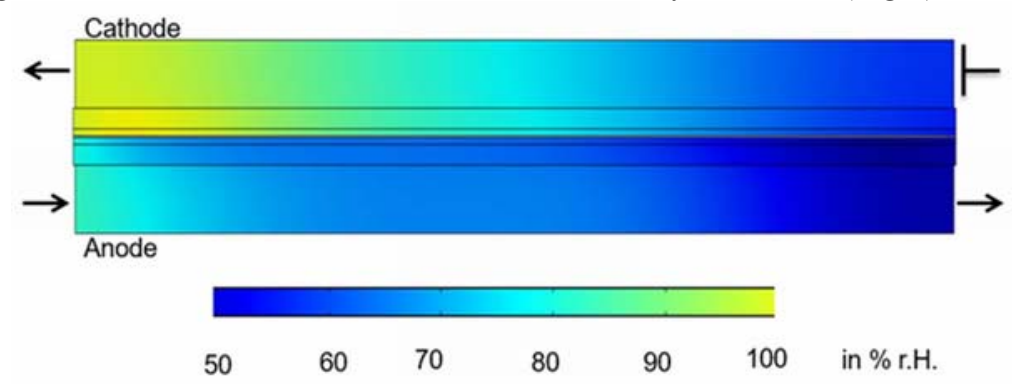

Fig.8. Results of the simulated relative humidity of the EHC.

\subsection{Electric Power Consumption}

Fig.9 shows the recorded U/I HP-characteristic of a $60 \% \mathrm{H} 2$ gas mixture at the temperature of $80{ }^{\circ} \mathrm{C}$ and a relative humidity of $80 \%$. It is compared with the U/I characteristic of the pure hydrogen with the same humidification and temperature. It should be noted that the flatter the U/I characteristic, the better the efficiency. Due to the lower limit of the MFCs, the range of the activating voltage at low currents is not shown.

HP studies with a hydrogen-gas mixture or pure hydrogen show increasing mass transport limitations at higher flows. Mass transport limitations due to decreasing mole fraction of hydrogen hinder the transport of the gas through the GDL to the anode. As a result, there is an increase in the voltage and energy consumption and thus, the efficiency of the Hydrogen Pump is lowered. 


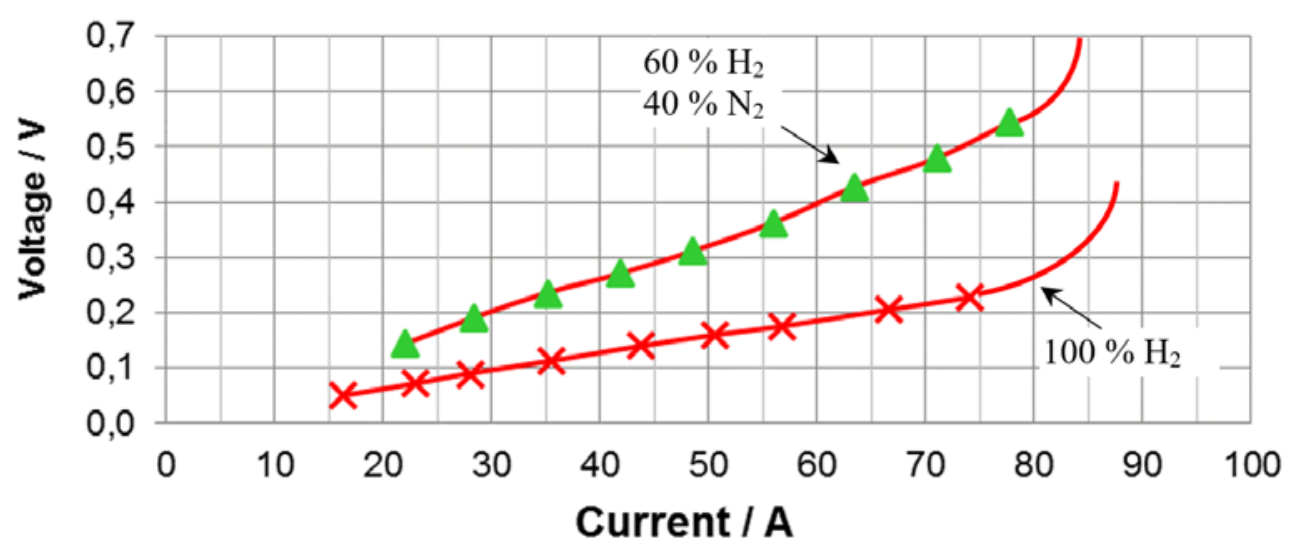

Fig.9. U / I characteristics of the $\mathrm{HP}$ with variation of the gas composition at $80^{\circ} \mathrm{C}$ and $80 \%$ r.H.

To validate the use of a hydrogen pump in the vehicle system, a dynamic FC vehicle model was created consisting of the models shown in Fig. 10.

This model was parameterized with real values and the dynamic behaviour as well as the fuel consumption were examined. The base vehicle for the simulation was a mid-range vehicle. The model parameters of the FC vehicle are listed in Table.1. These parameters are needed to determine the required transport processes in the FC and HP, the energy consumption and the efficiency of the powertrain in the vehicle driving cycles NEDC or WLTP.

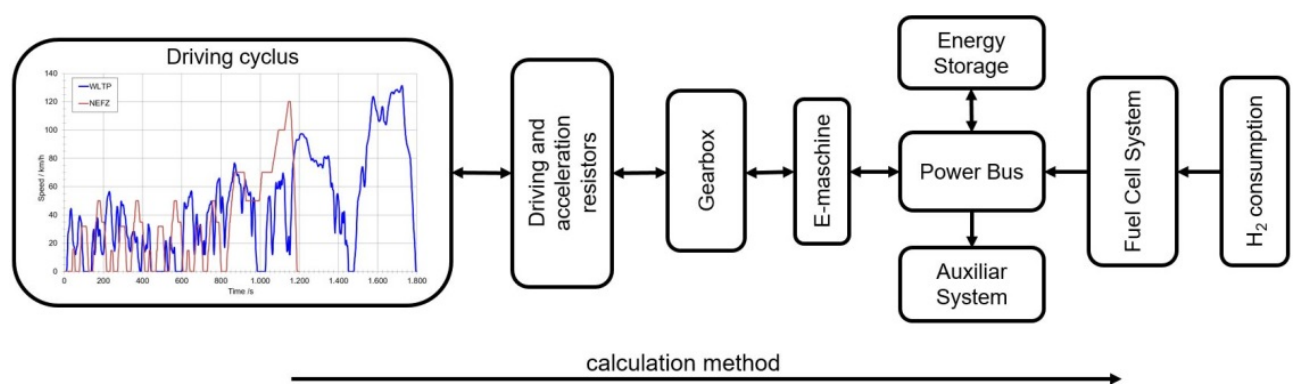

Fig.10. Structure for the calculation model for an FC vehicle

Based on the speed profile of the driving cycles, the vehicle data and the physical efficiency chain, it was possible to determine the performance losses of individual components as well as the hydrogen consumption of the entire system.

For comparison with conventional vehicles, the HP was compared to the event-driven purge strategy. In the event-driven purge strategy, the purge valve is opened when it reaches a defined nitrogen content in the anode circuit of the FC system and closed again after purging with the aim of minimizing the unused released hydrogen. In this simulation, the purge valve was opened when nitrogen content reached $5 \%$ and closed again when it fell below $2 \%$.

To use the equations for the FC-vehicle simulation model, it was necessary to determine the average energy from tank to wheel in the WLTP. The main consideration of this study was the hydrogen recirculation cycle. The $\mathrm{H} 2$ losses purged to the environment and the energy intake of the recirculation pump were determined. 
Table 1. Vehicle model parameters

\begin{tabular}{|l|l|r|l|}
\hline Vehicle model parameters & Symbol & Values & Units \\
\hline Vehicle total mass & $\mathrm{m}$ & 1300 & $\mathrm{Kg}$ \\
\hline Aerodynamic drag coefficient & $\mathrm{cW}$ & 0,25 & \\
\hline Frontal area & $\mathrm{A}$ & 2 & $\mathrm{~m}^{2}$ \\
\hline Tire drag coefficient & $\mathrm{cr}$ & 0,012 & \\
\hline Tire size & & $215 / 55 \mathrm{R} 17$ & \\
\hline Effective rolling radius of wheel & & 0,345 & $\mathrm{~m}$ \\
\hline Auxiliaries consumption & & $95 \%$ & $\mathrm{~kW}$ \\
\hline Walk \& Slip efficiency & & $95 \%$ & \\
\hline Transmission efficiency & & $90 \%$ & \\
\hline Engine efficiency & $95 \%$ & \\
\hline Converter efficiency & $90 \%$ & \\
\hline Battery efficiency & & & \\
\hline
\end{tabular}

An energy flow diagram with the event-driven purge strategy with jet pump and blower is shown in Fig.11. The colour assignment represents the energy in the hydrogen in red, the electrical energy is green, and the heat or loss energy is yellow.

In this calculation, the energy consumption of the recirculation pump was $170 \mathrm{Wh}$ and the purge loss was $559 \mathrm{Wh}$, which equates to $7 \%$ of unused hydrogen from the tank.

Similarly, an energy flow diagram with the feedback with HP and jet pump is showed in Fig.12. The simulation shows that the recirculation with a HP leads to a hydrogen loss by purge of $27 \mathrm{Wh}$ and the energy consumption of the HP is $83 \mathrm{Wh}$.

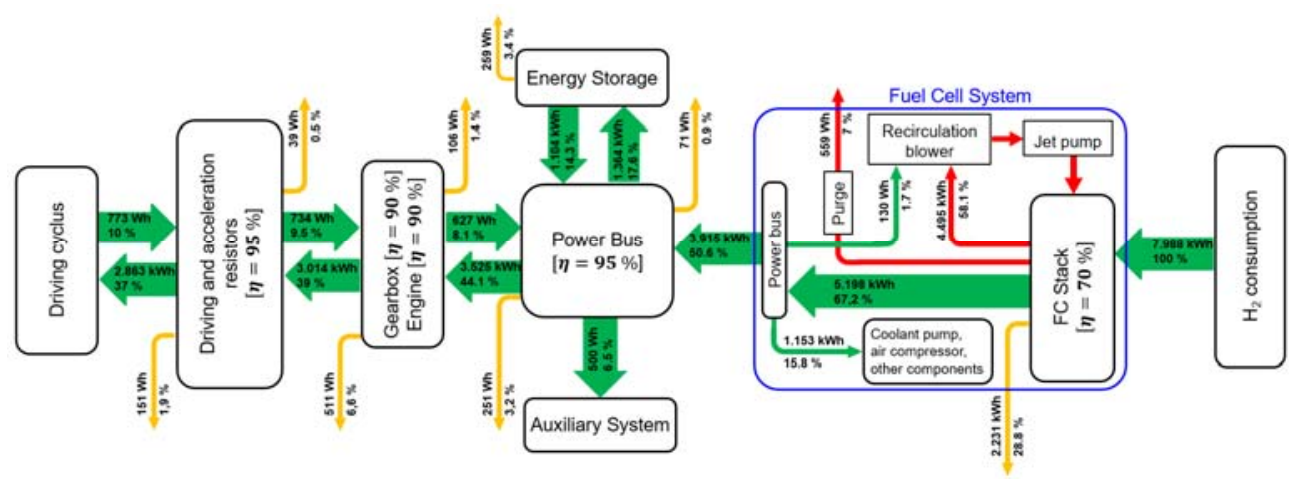

Fig.11. Energy flow on WLTP with jet pump and blower recirculation

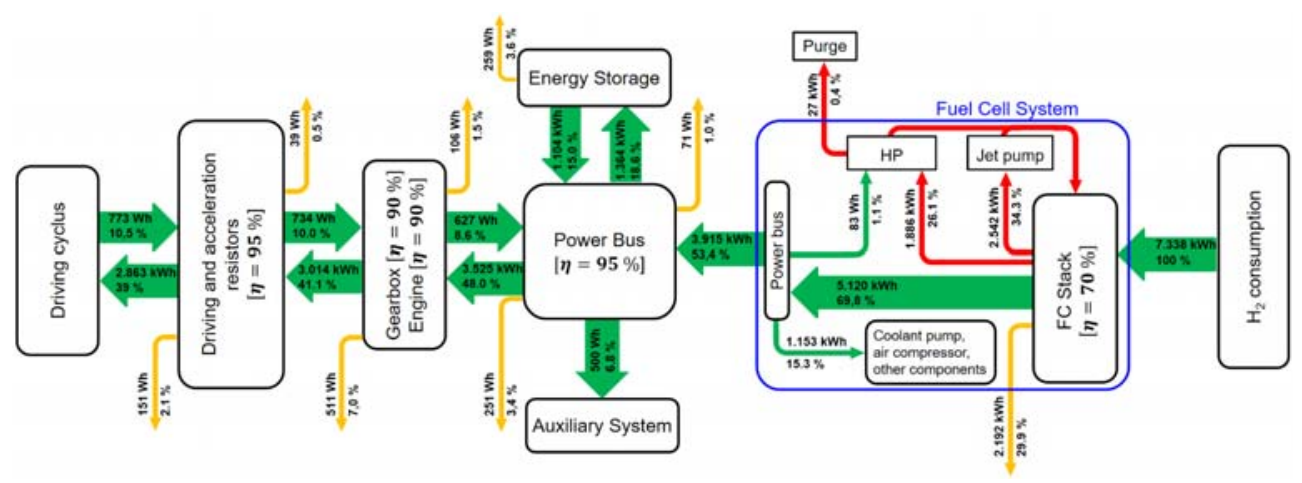

Fig.12. Energy flow on WLTP with jet pump and HP recirculation 


\subsection{Mechanical Integration of HP}

The installation of the HP in the anode circuit of the FC system can be realized in two ways (Fig.13).

Alternative A - Here, the HP is compressed in serial with the FC stack. The result is a dual stack that is $30-60 \mathrm{~mm}$ longer than a typical FC stack. This structure has the best space use in the vehicle and saves additional components such as pipes and hoses. In addition, similar or same types of MEAs and bipolar plates can be used for the HP and FC.

Alternative B - Here, the HP stack is placed in front of the FC stack so that fresh hydrogen from the tank flows through the HP cathode side. On the cathode side, the pumped humidified hydrogen is mixed with the fresh hydrogen from the tank. Therefore, the dry hydrogen from the tank is humidified. As described in chapter 3.2, a water transfer takes place from the anode to the cathode side of the HP. This process is limited by the saturation of the hydrogen on the cathode side of the HP. Since dry hydrogen flows through the cathode from the tank, more water can be transported from the anode to the cathode of the HP. This leads to a better humidification of the hydrogen and to a better anode-side FC stack humidification. A reduction in size or elimination of the FC cathode humidifier can achieved with further optimization of the system.

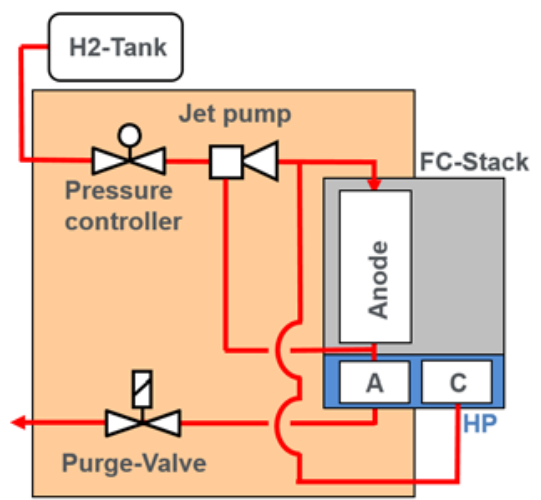

Alternative A

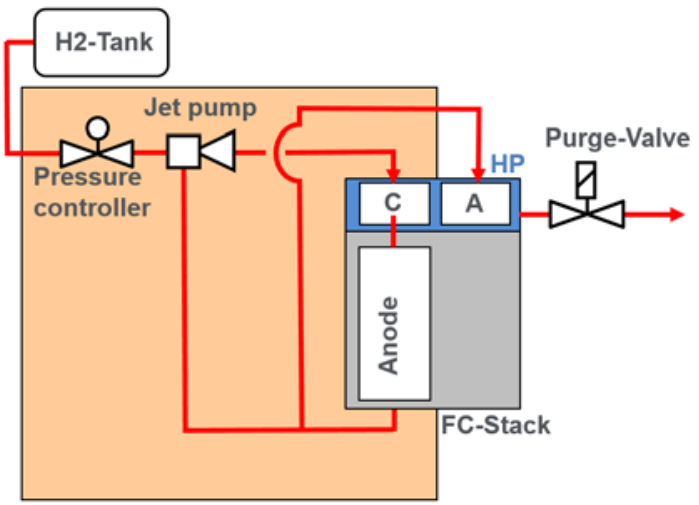

Alternative B

Fig.13. Mechanical integration of HP in FC-system 


\section{Conclusions}

The simulations showed that replacing the blower with the HP reduces the hydrogen loss from the purge in the WLTP from $559 \mathrm{Wh}$ to $27 \mathrm{Wh}$. This means that the loss of hydrogen can be reduced by up to $\sim 95 \%$.

Through the use of a hydrogen pump, the efficiency of the FC system could be further improved by $\sim 2,8 \%$ and the tank to wheel efficiency could be improved by $\sim 2 \%$. For example, hydrogen consumption is lower with the HP and the efficiency of a FC vehicle could be increased from $37 \%$ to $39 \%$.

Due to the capability for considerable hydrogen recovery, the HP has a significant advantage over the recirculation blower and the jet pump. The purity of the hydrogen at the cathode outlet of the HP also leads to an increased partial pressure of the hydrogen at the fuel cell and thus increases its efficiency. This results in a better overall efficiency of the FC system.

The HP has no moving parts, and thus it requires little maintenance, operates quietly, and is very robust. By using the same components as in the FC such as flow fields and GDLs, production costs can be saved. Additionally, the design in series with FC can reduce the weight and volume of the FC system, which further increase efficiencies.

Thus, the hydrogen pump has a high potential for use in the recirculation of hydrogen in FC systems in the automotive industry and is a great alternative to today's recirculation blower. The HP could play a vital role in the evolution of fuel cell vehicles and help to decrease the hydrogen consumption, resulting in more energy-efficient and greener mobility in the future.

\section{References}

[1] F. Barbir, H. Görgünm, Electrochim. Acta 2007, 37, 359.

[2] J.M. Sedlak, J.F. Austin, A.B. LaConti, J. Hydrogen Energy 1981, 6, 45.

[3] B. Rohland, K. Eberle, R. Ströbel, J. Scholta, J. Garche, Electrochim Acta, 1998, 43, 3629.

[4] R. Ströbel, M. Oscipok, M. Fasil, B. Rohland, L. Jörissen, J. Garche, J. Power Sources 2002, 105, 208.

[5] T. Schwarz, Ph. D. Thesis, Technische Universität, Clausthal, Germany, 2010.

[6] R. Staeck, Ph. D. Thesis, Technische Universität, Braunschweig, Germany. 2013.

[7] O. Berger, Ph. D. Thesis, Universität, Duisburg-Essen, Germany, 2009.

[8] M. Mayur, S. Strahl, A. Husar, W. Bessler, J.Hydrogen Energy, 2015, 40, 16466. 